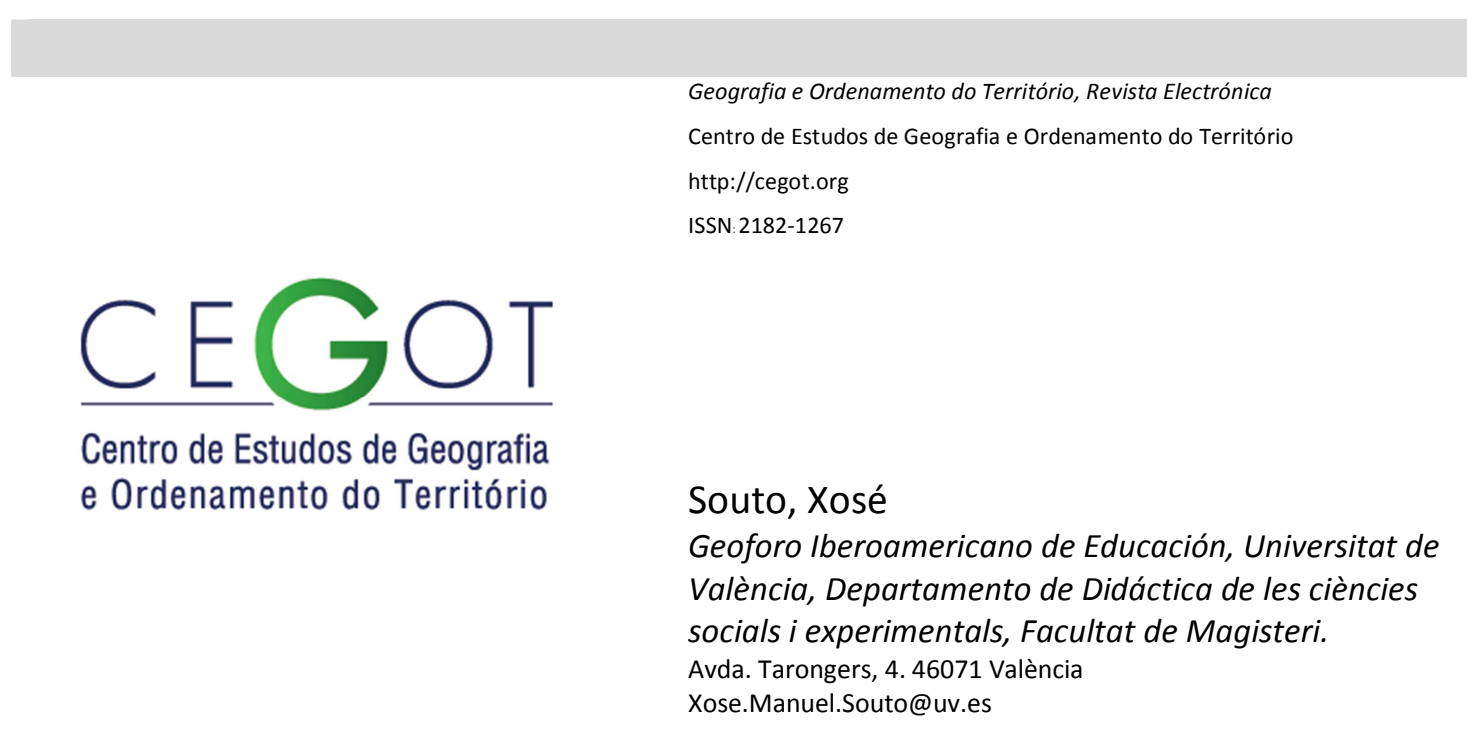

\title{
La gestión territorial europea en el noroeste de la Península Ibérica. Lecciones de una crisis
}

Referência: Souto, Xosé (2015). La gestión territorial europea en el noroeste de la Península Ibérica. Lecciones de una crisis. (GOT), n.o 7 (junho). Centro de Estudos de Geografia e Ordenamento do Território, p. 301-325, dx.doi.org/10.17127/got/2015.7.014

\section{Resumen}

La gestión del territorio es un asunto complejo. Para aconsejar el desarrollo de un medio es preciso conocer su contexto en diferentes escalas. La experiencia de los casos de regiones europeas y municipios de España nos muestra la necesidad de contar con una metodología que sea algo más que el dominio de técnicas del proceso de información. La crisis del modelo de crecimiento de la Unión Europea nos ofrece la posibilidad de argumentar con algunos casos, que se convierten en lecciones para el futuro en otros medios geográficos. Las imágenes espaciales del territorio constituyen un elemento básico en este diagnóstico.

Palabras clave: Unión Europea, Planeamiento regional, Desarrollo local, Gestión territorial.

\section{Resumo}

A gestão territorial europeia no noroeste da Península Ibérica. Lições de uma crise.

A gestão do território é um assunto complexo. Para aconselhar o desenvolvimento de um território, é necessário conhecer o seu contexto em diferentes escalas. A experiência dos casos de regiões europeias e municípios da Espanha demonstra-nos a necessidade de contar com uma metodologia que seja algo mais que o domínio de técnicas do processo de informação. A crise do modelo de crescimento da União Europeia oferece-nos a possibilidade de argumentar com alguns casos, que se convertem em lições para o futuro 
noutros meios geográficos. As imagens espaciais do território constituem um elemento básico neste diagnóstico.

Palavras-chave: União Europeia, Planeamento regional, Desenvolvimento local, Gestão territorial

\begin{abstract}
European territorial management in the nortwest of Iberian Peninsula. Lessons from a crisis.

Territorial management is a complex issue. We need to know the context of a spatial environment in order to advise its development at different levels. Our experience with European regions and Spanish city councils shows us the need of a methodology which goes beyond to manage of the informational process techniques. The crisis of the European Union growth model offers the possibility of dealing with some cases which become into future models for other geographical environments. Spatial views constitute a essential element for this diagnoses.
\end{abstract}

Key words: European Union, Regional Planning, Local Development, Territorial management

Un territorio tan extenso y heterogéneo como es la Unión Europea determina la existencia de numerosos intereses sociales, económicos y culturales. Todos ellos confluyen históricamente en modelos de planificación, que se presentan mediante un conjunto de informes, memorias y datos para justificar una acción futura sobre el medio. Las memorias y las acciones consecuentes crean un estado de opinión que naturaliza los factores históricos, de tal manera que la forma de las ciudades parece el resultado lógico de una fuerza natural. Dicha naturalización influye en las percepciones de las personas, por lo que es preciso cuestionar las concepciones espontáneas de la población para poder argumentar sobre el futuro. La crisis de las ideas que supone un crecimiento y expansión infinita es una oportunidad para pensar en las claves de la ordenación del medio.

Ordenar supone explicar un discurso que busca legitimar una decisión sobre el territorio. Juzgo que es difícil entender lo que es la gestión territorial y por qué ésta precisa de un discurso deliberativo si no explicamos la dualidad de saber y poder, de un conocimiento de los hechos (lo causado y racional) y un conocimiento de la acción (lo motivado y razonable). La pregunta "¿por qué?" tiene dos significados y supone dos formas de explicación, es decir que busca dos especies (diferentes aunque complementarias) de conocimiento: la de 
aquello que no puede ser de otra manera y la de aquello que puede ser de otra manera. La planificación urbana afecta al bienestar de las personas y como tal supone un juicio de valor de las previsibles consecuencias de su ejecución y, en coherencia con lo manifestado, se presenta como lo que no puede ser de otra manera. Es decir, la argumentación no sólo es científica y objetiva (relaciones causa>efecto), sino que hacen referencia a valoraciones éticas y en ciertas ocasiones supone la elaboración de un juicio moral anterior a la misma argumentación, que se realiza "post facto" ${ }^{1}$.

Para poder optar entre una manera u otra de hacer se ha de considerar no sólo el discurso, sino los contextos en que éstos se producen. Mantengo la idea de que es imposible desarrollar una actuación de participación ciudadana con el actual sistema de gestión del territorio, pues éste se ha convertido en una mercancía regulada por sistemas de poder financiero y político. Trataré de argumentar estas cuestiones con ejemplos de casos territoriales de la Península Ibérica, después de 1986, cuando España y Portugal ingresan en la Comunidad Europea (luego Unión Europea a partir de 1993). Este cuestionamiento de la participación es uno de las finalidades políticas de la UE, como se puede comprobar en el desarrollo de la Iniciativa ciudadana europea ${ }^{2}$.

Para valorar los casos analizados he procedido a comparar las estrategias de planeamiento y algunos resultados que surgen de la interpretación de los datos estadísticos. No se pretende justificar en este caso una metodología positivista, con el apoyo de los datos "objetivos", sino presentar unas tendencias de evolución que nos permitirán el análisis de los agentes sociales que intervienen en la gestión territorial. Así los métodos cualitativos (entrevistas, grupos de discusión) han sido las fuentes básicas del trabajo que ahora presentamos (Perecman, 2006). Es decir, se pretende realizar una hermenéutica de los discursos oficiales para explicar los recelos y desconfianzas que surgen en la gestión cotidiana del territorio.

\footnotetext{
${ }^{1}$ Sobre la argumentación en historia y ciencias sociales podemos consultar: Haidt, Jonathan.(2001) The emotional dog and its rational tail. A social intuitionist approach to moral judgment, Psycological Review, vol. 108, núm. 4, pp. 814-834.Traducción: El perro emocional y su cola racional: un enfoque intuicionista social del juicio moral, en Cortina, Adela (edición). Neurofilosofía Práctica, Granada: Editorial Comares (Guía Comares de...), 2012, pp.159-215

${ }^{2}$ Nos referimos a la Iniciativa Ciudadana Europea, que es una invitación para que la Comisión Europea proponga un texto legislativo en alguno de los ámbitos de competencia de la UE. Las iniciativas ciudadanas deben recibir el apoyo de, al menos, un millón de ciudadanos de siete de los veintiocho Estados miembros de la UE
} 


\section{1.-La banalización de los discursos argumentativos}

Jürgen Habermas en su Teoría de la Acción Comunicativa plantea que sólo es posible un diálogo sincero, una verdadera comunicación libre, cuando se produce una situación ideal de habla ${ }^{3}$. Para Habermas el lenguaje humano conduce al diálogo en una acción comunicativa; sin embargo, esta posición no se registra en los momentos de participación ciudadana en el planeamiento territorial. Es más, lo que sostengo es que el lenguaje se utiliza como un instrumento de dominio por medio de dos técnicas complementarias: la creación de una jerga tecnocrática, que trata de alejar al ciudadano de los problemas que le competen, y la banalización de ciertas reivindicaciones, como el desarrollo sostenible o la integración del medio rural y urbano. Todo ello bajo el dominio técnico de las empresas de comunicación de masas, que crean una opinión pública que se difunde a través de las correspondientes representaciones sociales.

De esta manera podemos formular una hipótesis principal para organizar este trabajo: $L a$ hegemonía cultural procedente de la racionalidad financiera se ha impuesto sobre las potencialidades ecológicas del medio. Ello ha supuesto procesos de segregación y marginación social en las ciudades y entre éstas y el medio rural, así como en otras escalas entre los territorios del norte y oeste europeo respecto al sur. Un ejemplo evidente es la utilización de los acrónimos de los países que han pedido mayores ayudas económicas a la Unión Europea (Portugal, Italia, Irlanda, Grecia y España) con un nombre claramente peyorativo: Piigs. Pero sobre todo donde es más evidente el contraste entre los equipamientos es en el acceso a los servicios públicos ${ }^{4}$. Una perspectiva geográfica de la gestión urbanística necesita saber combinar las escalas espaciales para descubrir los

\footnotetext{
${ }^{3}$ Nos ha interesado la figura y obra de Jürgen Habermas porque analiza críticamente los discursos en un contexto social. Sin embargo hemos considerado también la figura de su discípulo A. Honneth, pues supera la idealización de la situación ideal de habla a través de un análisis individual y social de los hechos que agradan y desagradan a las personas en las interacciones colectivas. Para mayor información podemos consultar: Habermas, J. (1987), así como la interpretación que hace Mc Cartyhy (1987).

${ }^{4}$ El estudio de Navarro, Vicenç. Bienestar insuficiente, democracia incompleta, Barcelona, Anagrama, 2001, especialmente en las páginas 35-36 en las que sintetiza estudios anteriores y contrasta la tasa de empleo en servicios del Estado del bienestar en los países nórdicos (18\%) muy superior a la registrada en España. En las páginas 56 a 69 nos presenta ejemplos concretos de la política social de los países nórdicos que ha permitido crear empleo y mantener una elevada productividad, en gran medida como consecuencia de su política de comercio exterior.
} 
factores ocultos que legitiman una determinada acción ${ }^{5} . Y$, por otra parte, cualquier argumentación positivista requiere, desde mi posición ética, un fundamento filosófico y social; en este sentido las teorías del capital cultural de P. Bourdieu y la legitimación del aprecio desde la posición de Honneth son elementos que condicionan las lecturas desde los datos econométricos y territoriales.

Para poder entender las directrices políticas de la Unión Europea es preciso considerar su origen histórico. Así los primeros pasos institucionales coinciden con la gestión de los fondos económicos procedentes de Estados Unidos para reconstruir el territorio europeo tras su destrucción en la contienda bélica de la Segunda Guerra Mundial (el denominado Plan Marshall); surge así la Organización Europea de Cooperación Económica (OECE), luego transformada en escala mundial en la Organización de Cooperación y Desarrollo Económico (OCDE), que impulsa y gestiona fondos económicos para llevar a los diferentes países a la ruta del neoliberalismo económico. Igualmente la constitución de la asociación comercial entre Bélgica, Holanda y Luxemburgo (BENELUX) y la Comunidad Europea del Carbón y Acero (CECA) son instituciones seminales de la Comunidad Económica Europea (CEE) que luego daría lugar a la Unión Europea. Un proceso económico que busca la alianza, cuando no la sumisión, a las directrices estratégicas de las grandes empresas multinacionales radicadas en Estados Unidos, como se puede comprobar en las negociaciones del Tratado de Libre Comercio entre Estados Unidos y la Unión Europea ${ }^{6}$.

Una primera lección que debemos tener presente en la gestión democrática del territorio es el análisis de los discursos que se producen en el campo de la gestión urbanística, considerando de una manera especial la representación social del territorio, que se proyecta como imagen de orden/desorden social. Los estudios de las concepciones sociales y sus

\footnotetext{
${ }^{5}$ Este artículo se ha redactado desde la experiencia de los cursos de grado y postgrado impartidos en universidades ibéricas (Valencia, Santiago de Compostela y Lisboa), pero sobre todo revisando mi propia participación como director de los Segundos Estudos Estratéxicos do Eixo Atlántico (2003-2005) en la que participaron las seis universidades públicas de Galiza y Norte de Portugal además de expertos en el planeamiento euro-regional.

${ }^{6}$ Nos referimos al Tratado conocidos por sus siglas inglesas TIPP (Transatlantic Trade and Investment Partnership) que se negocia en los años 2013 y 2104, que supondrá la eliminación de trabas legislativas (arancelarias y ambientales) a la explotación de los recursos por las multinacionales.
} 
representaciones ${ }^{7}$ nos deben ayudar a entender estos mensajes y sus consecuencias en la imagen mental de los ciudadanos. Un camino que ya hace décadas se inició en las ciencias geográficas en relación con el paradigma de la Percepción y el Comportamiento y que ha tenido una clara incidencia en el análisis del planeamiento urbano (Capel, 1973; Boira, 2003).

Además desde el ámbito de la gestión territorial se ha intentado desarrollar una nueva teoría que supusiera la legitimación de estas acciones, como ha sido en el campo del planeamiento estratégico ${ }^{8}$. Desde la posición teórica de Habermas se intenta alcanzar un acuerdo entre las instituciones y los denominados agentes sociales (Farinós y Romero, 2007; Mañero, 2010); sin embargo desde otras posiciones se alude a la hipocresía social en el planeamiento territorial, pues se limita a una posición simbólica (Borja, 2012, Harvey, 2013), lo que está más en consonancia con las posiciones teóricas de Honneth ${ }^{9}$.

Un caso evidente de la hipocresía social es la ocultación del fracaso político de la Unión Europea (UE). La frustración en la elaboración política de una Constitución europea es el punto y seguido de fracasos anteriores, como la Comunidad Política Europea de 1952 o las continuas reticencias de Gran Bretaña a la configuración de un espacio social europeo, o los rechazos del euro en numerosos países de la UE. Pero sobre todo es la negativa en referéndum de algunos países como Francia, Irlanda u Holanda a las políticas diseñadas en las instancias burocráticas de la UE, como en relación con su ampliación y programas políticos. Por eso los discursos generados en sus instituciones deben ser analizados con rigor, evitando el estereotipo de la modernidad europea.

En el año 2014 el mapa de la Unión Europea (ver figura 1) comprendía 28 países, que ha sido el resultado de sucesivas incorporaciones desde los seis socios fundadores que institucionalizan la Comunidad Económica Europea a través del Tratado de Roma en 1957 que se convierten en doce en 1986, en veinticinco en 2004, hasta la última adhesión de

\footnotetext{
${ }^{7}$ Los estudios de las representaciones sociales suponen un esfuerzo para conciliar la explicación de los aspectos volitivos y subjetivos con los cognoscitivos y sociales. A este respecto se pueden consultar los trabajos clásicos de Moscovici (1975) y Jodelet (1984), así como los más recientes de Castorina (2000)

8 Me refiero al trabajo de Josep María Pascual, prestigioso economista y sociólogo que ha fomentado y difundido la gobernanza democrática desde la AERYC (África, América, Europa de Regiones y Ciudades. Postula la superación de los problemas urbanos a través de la participación institucional. Igualmente sobre este asunto se puede consultar el trabajo de Fernando Mañero (2010)

${ }^{9}$ Es el ejemplo de Jordi Borja (2012)
} 
Croacia en 2013. Una ampliación que ha dado lugar a que las diferencias culturales, sociales y ambientales se transformaran en desigualdades de acceso al bienestar socioeconómico.

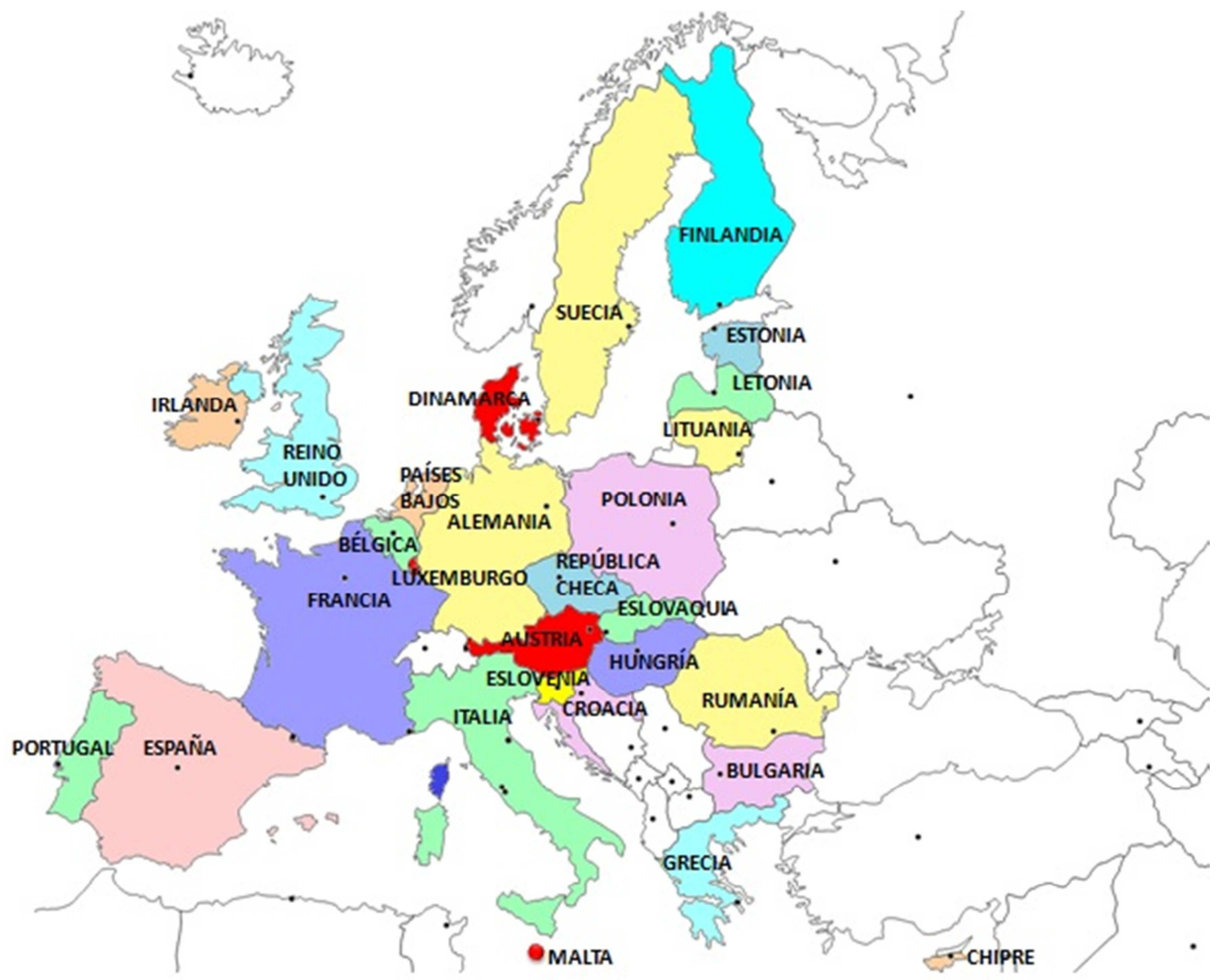

Figura 1. Mapa de la Unión Europea en 2014. Fuente: Cartografía básica de la UE

¿Cómo tratan de influir en la opinión pública desde estas instituciones?, ¿Cómo se difunden estos discursos? ¿Cómo influyen en la percepción del futuro ordenado y planificado desde las élites políticas? Fundamentalmente a través de una estrategia que muestra, desde el marketing territorial, las ventajas de una alianza entre Estados para superar los problemas derivados de la situación anterior a la Segunda Guerra Mundial: conflictos étnicos y las desigualdades económicas. El planeamiento se "vende" como un programa de cohesión territorial y de convergencia entre los países y regiones que conforman la UE.

En el cuadro 1 pretendemos resumir los principios fundamentales que se esperaban alcanzar por parte de la UE respecto al planeamiento territorial. Como podemos apreciar se hace referencia explícita al planeamiento regional, pero al mismo tiempo se indica la necesidad de una competitividad regional a través de una economía fuerte. 


\begin{tabular}{|c|c|}
\hline Prioridades & Presupuestos \\
\hline $\begin{array}{l}\text { Promover el desarrollo territorial policéntrico y } \\
\text { equilibrado }\end{array}$ & Aplicar un desarrollo local y regional integrado \\
\hline $\begin{array}{l}\text { Estimular el desarrollo integrado en las ciudades y } \\
\text { en el medio rural }\end{array}$ & $\begin{array}{l}\text { Considerar la política de cohesión y desarrollo } \\
\text { rural como parte fundamental del desarrollo } \\
\text { integrado }\end{array}$ \\
\hline $\begin{array}{l}\text { Integrar territorialmente las regiones } \\
\text { transnacionales y fronterizas }\end{array}$ & $\begin{array}{l}\text { Reforzar los mecanismos que aseguren la } \\
\text { coordinación territorial }\end{array}$ \\
\hline $\begin{array}{l}\text { Asegurar la competitividad regional basada en la } \\
\text { economía local fuerte }\end{array}$ & $\begin{array}{l}\text { Mejorar la coordinación de los diferentes fondos } \\
\text { en una política regional }\end{array}$ \\
\hline $\begin{array}{l}\text { Mejorar la conectividad territorial para } \\
\text { individuos, comunidades y empresas }\end{array}$ & $\begin{array}{l}\text { Mejorar la dimensión territorial de la planificación } \\
\text { estratégica }\end{array}$ \\
\hline \multirow[t]{2}{*}{$\begin{array}{l}\text { Gestionar e interrelacionar la riqueza paisajística, } \\
\text { ecológica y cultural }\end{array}$} & $\begin{array}{l}\text { Estimular nuevas experimentaciones de desarrollo } \\
\text { regional y local }\end{array}$ \\
\hline & Implicar a actores regionales y locales \\
\hline
\end{tabular}

Cuadro 1. Prioridades y estrategias en el planeamiento territorial europeo

Fuente: “Agenda territorial de I'Union européenne 2020 -- Vers une Europe inclusive, intelligente et durable, faite de régions diverses" / "Territorial Agenda 2020 - Towards an Inclusive, Smart and Sustainable Europe of Diverse Regions"

La banalización y creación de una jerga tecnocrática no sólo es algo que nos haya preocupado a nosotros. Otros profesionales de la Geografía lo han recogido en sus publicaciones; así es el caso de Andreu Ulied, que como señalan J. Romero y J. Farinós (2004), nos muestra un texto "muy sugerente y lleno de información cualitativa de gran interés", lo que es resultado de su amplio conocimiento sobre los actores de la ordenación territorial para Europa (op.cit.; 11). Con una sinceridad muy grande nos refleja sus impresiones y preocupaciones sobre la formulación teórica del marco en que se inscriben las políticas territoriales europeas: "Cuando apenas sí alcanzamos a describir los fenómenos que suceden, con nuestras pobres metáforas científicas, orgánicas, metálicas, cosmológicas, ¿cómo estar seguros de que nuestras propuestas de orden, de estructura territorial, no son

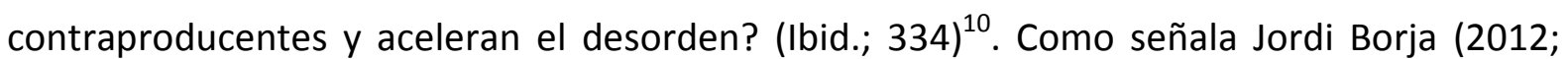
284) muchos de los conceptos que se utilizan, como gobernanza, son obstáculos para la participación y una legitimación del discurso tecnocrático.

En este sentido, podemos plantearnos chasta qué punto el policentrismo, que evoca la teoría clásica de Christaller, será capaz de frenar la dispersión, hoy denominada "ciudad

\footnotetext{
${ }^{10}$ En Souto González (2006, a) he analizado con detalle algunas publicaciones españolas que mostraban los ejes de la denominada "gobernanza" europea sobre el territorio
} 
difusa"? Será preciso analizar los intereses que subyacen a las palabras y retóricas creadas en los balnearios de Luxemburgo, pues bajo la noble reivindicación de autonomía local se esconden intereses inmobiliarios (Romero, J y Farinós, 2004; 328). Frente a las jergas institucionales parece necesario ensayar otras maneras de ejercitar la participación democrática ciudadana desde los sentimientos, la razón y el corazón, como bien entiende F. Pindado (2008), con su amplia experiencia empírica en el caso de Barcelona.

Se hace preciso explicar la presión política de unos intereses determinados y con unas estadísticas que no reproducen la realidad social y geográfica como sería de esperar. "Con esa información escasa, con teorías meritorias pero simplistas, construimos modelos explicativos y sistemas de previsión demográfica, económica, de transporte y energía" (op.cit.; 336). Desvelar así los factores ocultos que deforman la realidad social y territorial que se presenta en los medios de comunicación de masas.

Hay dos notas que me interesa subrayar en esta primera aproximación a la Estrategia Territorial Europea (ETE). La primera hace referencia al déficit democrático que se observa en la UE y, al mismo tiempo, los esfuerzos financieros que se dedican desde los Fondos Estructurales para integrar a los gobiernos regionales en la gestión del territorio, procurando la participación de la ciudadanía (programa de gobernanza, Agendas 21). Ahora bien, mi experiencia directa en la gestión de proyectos de desarrollo regional (Eixo Atlántico) y local (Agendas 21) me indica que la cuestión de la participación democrática es un proceso largo y complejo y que la tentación de control por parte de las autoridades locales todavía es muy grande. Tal parece como que habría que formular una educación democrática ciudadana de mayor alcance, tomando como referencia las buenas prácticas (Hart, 1993). O sea, creemos que hay que valorar positivamente que la ETE pueda significar una pieza más en el engranaje institucional que reconoce la necesidad de la participación; los fines parecen adecuados, otra cuestión es la metodología que se emplea, que muchas veces es incoherente con las metas propuestas. Por eso es necesario considerar los ejemplos prácticos que se han producido en la participación ciudadana dentro de la educación ambiental y el planeamiento (Boira, 2003, Reid, et al., 2008).

La segunda nota tiene que ver con la anterior. Supone una reflexión sobre el intento de transmitir las experiencias de las distintas tradiciones estatales al conjunto de la Unión. En este sentido puede ser muy oportuna la confluencia de experiencias dispares, como es la 
planificación regional centralizada en Francia y la descentralizada en Holanda o Alemania. Además se puede beneficiar de análisis realizados por algunos países para hacer frente a problemas concretos, así Holanda tenía un objetivo prioritario en la política regional: controlar el crecimiento disperso de la periferia urbana, preocupación común en otros lugares de la UE. O bien cómo combinar la gestión territorial en diferentes escalas, aprovechando la experiencia alemana de los länder.

En efecto, si la ETE supone una nueva visión global del conjunto del territorio europeo, "mediante un proceso abierto, participativo y consensuado" (Farinós y Romero, 2004; 46), lo que interesa conocer es cómo se gestiona este proceso participativo. Pues hasta el momento presente los derechos de propiedad privada, los beneficios empresariales y la institucionalización del poder político se han impuesto a otros intereses particulares y colectivos. El tránsito hacia los objetivos como "la triple C" (cooperación, concentración y competencia) nos muestran incertidumbres de difícil resolución: cómo combinar la competencia entre áreas con la cooperación entre iniciativas y organizaciones, si precisamente una de las claves de la competitividad estriba en ocultar las estrategias a los posibles competidores; algo que se pudo observar en los proyectos conjuntos de Eixo Atlántico, donde los alcaldes guardaban sus estrategias locales para que no se conocieran desde otros municipios, pues la lógica teórica del marketing territorial decía que "las ciudades competían".

\section{2.- Superar el localismo bajo la apariencia de una identidad compartida.}

La segunda lección nos indica que la gestión del planeamiento regional europeo está condicionada por las estrategias de orden superior. El marketing territorial afecta a la manera de presentar el discurso para poder optar a la financiación de los fondos europeos. Para ello se busca insertar las necesidades locales en las ofertas institucionales europeas. Un caso evidente es el proceso de construcción de una identidad compartida para diseñar una gestión territorial policéntrica en la euro-región del Noroeste peninsular. Un estudio de caso 
que nos permite ver la diferencia entre los deseos y las acciones, entre las palabras y los hechos.

A la altura del tránsito del segundo al tercer milenio de nuestra era parece evidente que las innovaciones técnicas en las infraestructuras de transporte y comunicaciones implicaban un sistema urbano en red, donde los flujos y los nodos eran las características esenciales del mismo. Se necesitaba superar la gestión territorial desde el ámbito local, restringido a las competencias municipales y a las fronteras estatales. Romper con las ataduras de las fronteras fue un objetivo impulsado desde la UE, a través de sus programas financieros. Suponía que desde la base social, de acuerdo con los recursos ambientales, se debía diseñar un futuro deseable para la convivencia.

No obstante las líneas prioritarias del planeamiento estratégico, o sea el territorio que se aspiraba construir, estaban determinadas por las directrices de la Unión Europea, como podemos apreciar en esta síntesis histórica de dos períodos iniciales del siglo XXI (ver cuadro 2). Como vamos a comprobar muchos de estos conceptos van a aparecer en las políticas locales, pues sin ellas era muy difícil acceder a la financiación europea.

\begin{tabular}{|l|l|l|}
\hline Períodos & $2000-2006$ & $2007-2013$ \\
\hline Prioridades Estratégicas & $\begin{array}{l}\text { 1. Competitividad regional } \\
\text { 2. Estrategia para empleo } \\
\text { 3. Desarrollo rural e urbano } \\
\text { integrado }\end{array}$ & $\begin{array}{l}\text { 1.Desarrollo sustentable } \\
\text { 2. Ciudadanía europea: libertad, } \\
\text { justicia, acceso bienes } \\
\text { 3. Socio a escala mundial }\end{array}$ \\
\hline Principios fundamentales & 1.Desarrollo sustentable & $\begin{array}{l}\text { 1.Principios de gobernanza } \\
\text { 2.Crecimiento de la riqueza } \\
\text { 3.Papel en el escenario mundial }\end{array}$ \\
\hline
\end{tabular}

Cuadro 2. Directrices para los Programas de Desarrollo Regional

Fuente: COMISIÓN DAS COMUNIDADES EUROPEAS. Directrices dos Programas 2000-2006, COMISIÓN DAS COMUNIDADES EUROPEAS. Retos políticos y medios presupuestarios de la Unión ampliada (2007-2013)

En el caso de la Península Ibérica nos vamos a referir a un caso de gestión territorial bajo estas premisas. Tras la entrada de España y Portugal en la Unión Europea (1986) uno de los objetivos de los programas europeos, con su correspondiente financiación, consistía en 
integrar los territorios de ambos lados de las fronteras estatales. Ello suponía que desde los espacios fronterizos existiera una imagen mental que favoreciera la cercanía entre los pueblos. En este sentido Galicia y Norte de Portugal tenían un pasado histórico con finalidades culturales comunes, lo que facilitó la creación de una Comunidad euro-regional, constituida jurídicamente el 31 de octubre de $1991^{11}$. El encuadramiento espacial nos muestra que la euro-región se situaba en la periferia peninsular, lo que significaba que era uno de los objetivos prioritarios de la estrategia europea de cohesión territorial. Para desarrollarla se ponen en marcha dos instrumentos de acción local diferentes.

Por una parte, en el año 1991 se constituía a Comunidade de Traballo Galiza-Norte de Portugal, impulsada por la Xunta de Galicia y la Comissão de Coordinação da Região Norte de Portugal, mientras que un año después se producía la declaración oficial (abril de 1992 en Porto) de la constitución de una entidad privada: O Eixo Atlántico (E.A.). Agrupaba a trece ciudades-municipios de Galiza y Norte de Portugal que formalizan su pacto el 28 de septiembre de ese mismo año en la ciudad de Viana do Castelo. Este pacto local se fue ampliando hasta 34 municipios en 2008 (ver figura 2) y desde el año 2000 se integra en la Comunidade de Traballo como comisión específica de desarrollo urbano ${ }^{12}$.

¿Por qué esta sorprendente duplicidad de un pacto local entre municipios? Para entender esta nueva paradoja es preciso comprender las directrices políticas de los principales partidos políticos y los intereses regionales del Norte de Portugal en relación con el resto del país. En efecto, el Pacto local do E.A. nace como contrapoder a la Comunidade de Traballo, impulsada por el alcalde de Porto (Fernando Gomes) y por el Partido socialista para presentar un deseo de alcanzar la identidad euro-regional desde los municipios, según ellos desde los ciudadanos frente a los territorios ${ }^{13}$. Esta oposición es un hito geográfico en la gestión territorial. Las políticas públicas de ordenación orientan el desarrollo territorial atendiendo muchas veces más a los recursos potenciales (entre los cuales se cuantifica el

\footnotetext{
${ }^{11}$ En la página web de Eixo Atlántico www.eixoatlantico.com podemos encontrar numerosas publicaciones sobre la euro-región. Para una síntesis del proceso organizativo se puede consultar L. Domínguez y N. Venade (2004) que presentan los aspectos básicos de la organización jurídica del pacto interestatal y la influencia de los fondos europeos.

${ }^{12}$ Sobre o Eixo Atlántico se puede consultar su página web y además los trabajos de Leonor de la Puente (2000), V. Paül (2001) y José Armas (2001).

13 La declaración inicial do Eixo Atlántico es bien elocuente de lo que decimos: "os anos noventa están chamados a ser no terreo europeo o paso decisivo no recoñecemento e institucionalización da Europa das cidades"
} 
recurso humano) que a las necesidades cotidianas del habitante del lugar ${ }^{14}$. ¿Significa esto que o Eixo Atlántico era una realidad asumida en su funcionamiento en la gestión y en la percepción de las y de los vecinos? No podemos responder afirmativamente a esta primera cuestión, pues como muestra Raul Marques (1999; 257-267) en las instituciones municipales todavía existe un escaso conocimiento, sobre todo en Galicia, respecto de los poderes locales, que son percibidos como gestores distantes de las preocupaciones de los vecinos. Sin embargo es un instrumento útil para crear una opinión pública favorable a la cooperación local, al desarrollo de los recursos (Pardellas, 2002) y a la participación ciudadana.

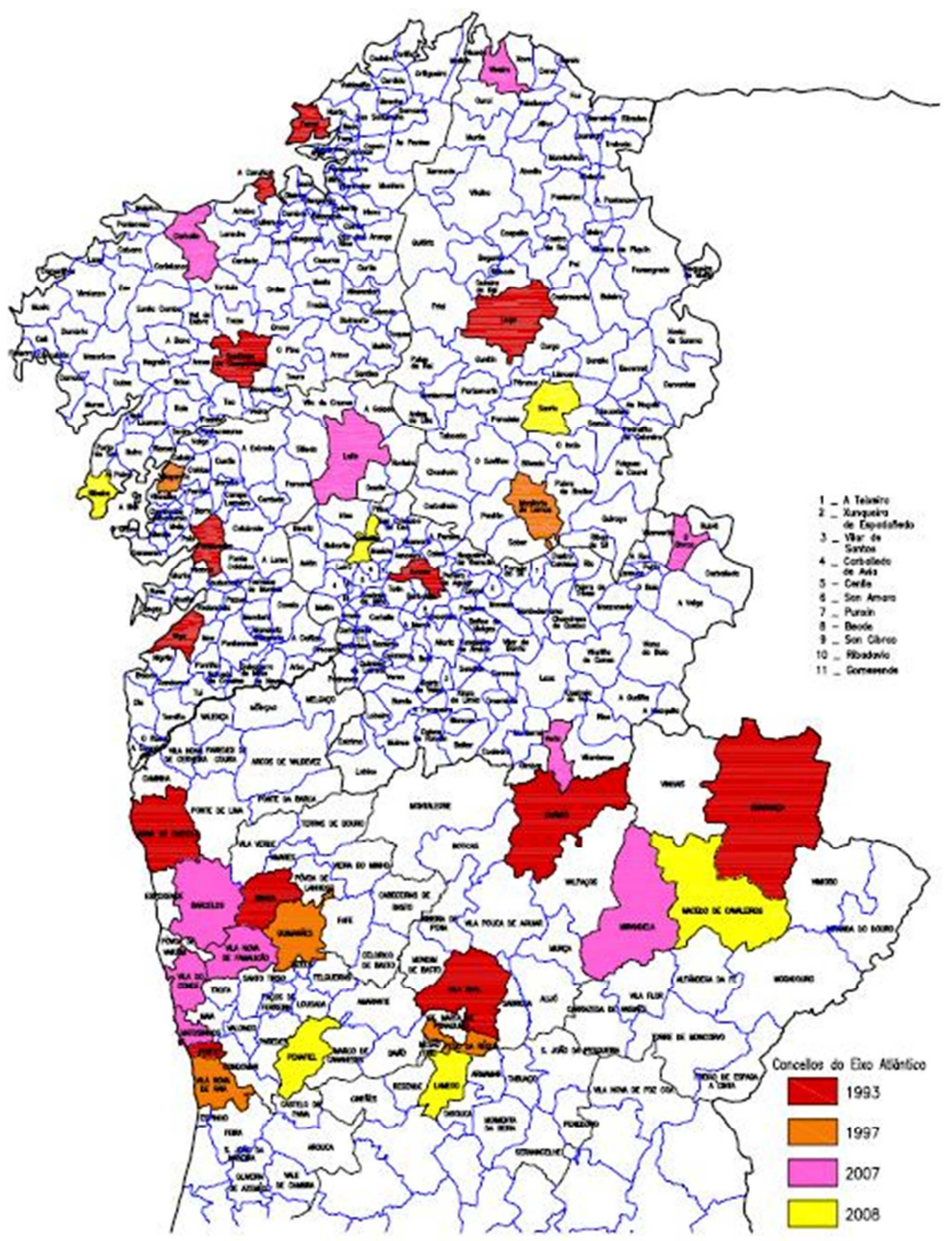

Figura 2: Municipios que establecen el pacto local do Eixo Atlántico.

Fuente: elaboración propia

\footnotetext{
${ }^{14}$ En Souto, 2005, analizamos con detalle el surgimiento y desarrollo del pacto local do Eixo Atlántico con sus diferentes instrumentos técnicos para facilitar la gestión territorial.
} 
Por eso mismo en los diferentes trabajos en los cuales he podido participar me ha interesado en especial la vinculación del planeamiento (estratégico o físico) con los deseos de calidad de vida en un determinado lugar. Para ello recurrimos a un análisis histórico de las relaciones entre los pueblos ${ }^{15} \mathrm{y}$ valoramos las aportaciones del marketing territorial en relación con los recursos del medio ${ }^{16}$ y finalmente evaluamos en el Plan Estratégico las necesidades de la vida cotidiana (Souto, Bouzada, Figueiredo, 2005).

\section{3.-Hacer visible las realidades ocultas en la gestión territorial}

Surge así una tercera lección para la gestión territorial: hacer visibles las desigualdades cotidianas, una visibilidad que aparece sobre todo en los momentos de crisis económica. Por eso es importante considerar la experiencia de E.A. y ver cómo se han fraguado los objetivos de los dos Estudos Estratéxicos y ver cómo se pueden interpretar las directrices técnicas desde una metodología sociocrítica. Los cambios que podemos observar en los Estudios Estratégicos del Eixo Atlántico, entre el primero y el segundo, están determinados por las políticas que antes hemos descrito en Europa (ver cuadro 3). Como vamos a mostrar con datos empíricos la visibilidad de la cooperación entre ciudades y territorio implicaba un análisis de los problemas sociales y demográficos.

\footnotetext{
${ }^{15}$ La historia compartida de las localidades del espacio euro-regional la podemos consultar en R. Villares (2010) e Souto, coord.. (1999).

${ }^{16}$ En lo referido a la búsqueda de una identidad patrimonial cultural (la piedra granítica de los monumentos) y ecológica (el agua de los ríos, rías y de la humedad en su vegetación) ha contribuido notablemente el estudio realizado por A. Cidrais con quien suscribe este artículo (Souto, 2001)
} 


\begin{tabular}{|c|c|}
\hline $\begin{array}{c}\text { Objetivos dos Primeros Estudios } \\
\text { Estratégicos (1993-94) }\end{array}$ & $\begin{array}{c}\text { Objetivos dos Segundos Estudios } \\
\text { Estratégicos (2004-2005) }\end{array}$ \\
\hline $\begin{array}{l}\text { - Mostrar los perfiles económicos terciarios de } \\
\text { las ciudades del Eixo } \\
\text { - Caracterizar el modelo territorial del Eixo } \\
\text { sobre los componentes demográficos, de } \\
\text { vivienda e infraestructuras } \\
\text { - Evaluar las nuevas dinámicas emergentes } \\
\text { - Mostrar un sistema urbano funcional en una } \\
\text { eurorregión rural, tratando de incorporar el } \\
\text { interior al dinamismo del litoral }\end{array}$ & $\begin{array}{l}\text { 2. Las competencias administrativas, procesos } \\
\text { sociales y organización del territorio. La } \\
\text { práctica de la gobernanza. } \\
\text { 3. Estrategias de visibilidad y cooperación entre } \\
\text { ciudades y otros lugares } \\
\text { 4. La complementariedad entre ciudades y } \\
\text { territorio: periurbanización } \\
\text { 5. Buscar la complementariedad del desarrollo } \\
\text { sustentable local: potenciar las buenas } \\
\text { prácticas }\end{array}$ \\
\hline
\end{tabular}

Cuadro 3. Comparación entre los Estudios Estratégicos

Fuente: Elaboración propia.

Para ello nos esforzamos en explicar que la disminución de las desigualdades entre territorios (los tres más pobres, España, Portugal y Grecia pasan del 68\% sobre la media del PIB europeo en el año 1988 hasta el 79\% en el año 1999), no suponía la eliminación de guetos urbanos y bolsas de pobreza en las áreas urbanas. De tal manera que para los Segundos Estudos Estratéxicos se priorizaron tres tipos de actuación; en primer lugar desarrollar las condiciones para el crecimiento del empleo en el seno de la competitividad regional; en segundo lugar una política de creación de empleo que implicara la lucha contra la exclusión social y, por último, un ordenamiento urbano y rural territorial equilibrado. Soy consciente de la dosis de ingenuidad de estas propuestas si no se controla el proceso de gestión del suelo, pero al menos se ofrecía a las autoridades políticas locales una voluntad de construir un proyecto colectivo desde el diagnóstico no sólo de los recursos, sino también de los problemas reales de la población, que son básicos para un desarrollo sustentable.

Entre las medidas propuestas vinculamos el desarrollo económico y tecnológico a la formación académica y a la creación de un espacio cultural que respetara las diferencias entre los pueblos e individuos. De tal manera que las infraestructuras de transporte quedaran sometidas a un plan de movilidad y las de comunicación e información a un proyecto de cultura ciudadana.

No es posible dar cuenta de las diferentes acciones que se programaron como consecuencia de estos Segundos Estudios Estratégicos, pues se editaron Agendas Estratégicas temáticas (transportes ferroviarios, aeroportuarios, autopistas marinas) y territoriales (asociaciones 
entre municipios del interior menos desarrollado). En dichas publicaciones ${ }^{17}$ se pueden consultar las líneas de actuación concretas para desarrollar un territorio euro-regional, dentro de la finalidad de crear una opinión crítica favorable a la cooperación intermunicipal.

En especial nos resulta significativa la expresión realizada por el coordinador de uno de los números de la Revista do Eixo Atlántico cuando expresamente dice que "Cooperar $e$ competir, esa é a cuestión" ${ }^{18}$; es decir, cuando se pretende solventar la paradoja que hemos anotado en páginas anteriores. Para ello, como se refleja en el artículo de Rui N. Baleiras (2009; 17-48) era preciso romper con las desigualdades existentes en la UE y controlar su proceso de la expansión a nuevos países. Esta dependencia de las inversiones europeas se reproduce en las críticas de los alcaldes del interior de la euro-región a las actuaciones do Eixo Atlántico, pues denuncian que este sigue primando las actuaciones de las zonas litorales, donde es bien cierto que se concentra la mayoría de la población ${ }^{19}$. Por tanto compaginar la cooperación con la competitividad es realmente complejo, sobre todo si se realiza sin una explicación convincente de la formación de las desigualdades territoriales.

\section{4.-Los principios discursivos y la participación local. El caso del Plan General de Vigo}

La aplicación de los principios tecnocráticos, diseñados en lugares lejanos, influye en la percepción del planeamiento local. La cuarta lección que aparece en este discurso indica que los intereses partidistas y la jerga tecnocrática se pretenden imponer como autoridad de criterio en el crecimiento urbano. La jerga creada por los poderes públicos, con el apoyo de los equipos de planeamiento, crea un obstáculo al conocimiento respecto al espacio vivido y deseado por los vecinos del lugar que se quiere gestionar.

Existen numerosos datos que se pueden transformar en resultados de una investigación a través de la interpretación teórica de los presupuestos de partida. Pero dichos datos deben

\footnotetext{
${ }^{17}$ En la página web de Eixo Atlántico se pueden consultar libremente en la sección de publicaciones

${ }^{18}$ Nos referimos al número 16 de Eixo Atlântico. Revista da Eurorrexión Galicia-Norte de Portugal, no 16, 2009, cuyo coordinador era el profesor de Ciencias Políticas de Vigo Enrique Varela.

${ }^{19}$ Ello se puede constatar en las asambleas y reuniones de los alcaldes do Eixo Atlántico, que después quedan reflejados en los correspondientes informes anuales.
} 
ser de acceso público y estar sometidos a la posibilidad de confirmación o refutación de los mismos en las pruebas empíricas. Para el caso que nos ocupa voy a utilizar datos de una escala local del municipio de Vigo, con poco más de 100 kms $^{2}$ y casi 300.000 habitantes en los años 2010-2014.

Voy a argumentar con los datos empíricos que dispongo, con las respuestas del equipo redactor del Plan General de Ordenación Municipal de Vigo, después de ser aprobado inicialmente por el pleno de 30 de diciembre de 2004 y ser presentadas más de 60.000 alegaciones ante este acto administrativo; proceso que continua después de la aprobación provisional de 19 de mayo de 2006. Con ello pretendo explicar que para analizar el "proceso discursivo de la planificación" es preciso conocer las intenciones ocultas y los intereses que se manifiestan en un proceso de construcción urbana.

El estudio de los informes para responder a las alegaciones presentadas ${ }^{20}$ nos indica cuál es el sentido del discurso técnico del equipo responsable de la redacción del Plan (Consultora Galega) y cómo se razonan los intereses de colectivos y personas ante la aprobación inicial. Igualmente trataremos de aportar nuestra perspectiva de análisis respecto al conflicto suscitado entre las administraciones locales y autonómicas respecto a la aprobación definitiva de dicho PGOM. En la planificación territorial no se trata tanto de argumentar con la causalidad de los hechos físicos, como analizar las intenciones históricas (el proyecto social y espacial) que manifiestan implícitamente los agentes sociales de la construcción urbana (Souto, 2005, a).

En diferentes respuestas a las alegaciones presentadas encontramos este tipo de respuesta: "A presente alegación ten o carácter de <alegación tipo> escrita por quen fose, pero preparada para recollida de firmas", "é outra das múltiples alegacións nas que sobre un escrito común se enganden a mán os datos de quen alega", "alegación tipo sin dúbida multicopiada varias veces..." (Alegacións 42463, 2212 e 19931 (modelos 076, 032 e 054)

Todas estas respuestas emitidas con fecha de diciembre de 2005 nos indican que el Equipo Técnico desconfía de la voluntad de quien escribe o suscribe dichas alegaciones, pues añaden datos a mano, fotocopian un mismo modelo, etc. No cabe pensar más bien que algún estado de opinión ha suscitado estas alegaciones tipo. Pero para poder analizar estas

\footnotetext{
${ }^{20}$ Las alegaciones están escritas en galego tal como se presentaron por los vecinos en el Ayuntamiento de Vigo.
} 
opiniones debe procederse de forma totalmente diferente a la que se expresa en algunas de las alegaciones: "unha opinión do alegante que por respecto non merece ser contestada, posto que carece de xustificación algunha", "as opinións discrepantes deben sustentarse en criterios obxectivos..." "as cuestións de opinión son só eso, opinión". Por eso no dudan en calificar de mala fe algunas alegaciones y los criterios esgrimidos se rechazan bajo la afirmación de que "a realidade vai máis aló do que ven quen escribeu este texto" (Alegacións 60986, 908 e 036).

El estudio de los informes y alegaciones emitidos por el Equipo Redactor están bien argumentados, o sea con eficacia, pues responden a un presupuesto de partida: el modelo de ciudad definido por ellos mismos. Pero no se trata de cuestionar las opiniones de los vecinos, como se hace, sino de saber qué tipo de ciudad piensan los vecinos y qué se puede hacer para negociar un modelo de ciudad que sea asumida por éstos, además de ser sostenible y permitir el crecimiento económico. Pero ello no entra dentro de la lógica y de la eficacia de los redactores: "O plan xeral non actúa por sensacións ou sentimentos..." como indica para desacreditar una alegación que presenta "motivacións intanxibles, de opinión" (49153, modelo 094). Una afirmación que sin duda es contraria a las investigaciones científicas procedentes del campo del cognitivismo y avaladas por recientes estudios empíricos de la neurociencia.

Por eso rechaza sin más opiniones de los vecinos, como es el caso de una reivindicación del plan de movilidad: "Descoñecese que se denomina <pacto por la movillidad> nin quen debera telo proposto. Non é contido do Plan Xeral" (4766, modelo 069). Y lo mismo cabría decir de otros aspectos paisajísticos y ambientales.

Entiendo que no hace faltan más datos empíricos para mostrar que en este contexto es imposible desarrollar una actuación que se pueda catalogar de "participación ciudadana", a no ser que por ésta se entienda la legitimación de las medidas previstas por parte del equipo redactor para desarrollar urbanísticamente el territorio. Resulta también interesante conocer los argumentos utilizados para aceptar parcialmente las alegaciones, sobre todo cuando estas proceden de uno de los grupos políticos que ha apoyado públicamente la aprobación del Plan. Así la justificación de la supresión del tramo sur de la Ronda de Vigo ("dende o nó de Balsa ata o municipio de Nigrán") hace alusión a que el carácter estructural que justificaba dicha vía, no era necesaria en la parte sur del municipio, ni siquiera para buscar un itinerario alternativo. Es decir lo que se venía justificando como resultado de los 
criterios objetivos del Plan ya no son tales, negando además el carácter de globalidad de dicho vial.

En consecuencia el meollo de la cuestión de la participación ciudadana se expresa en el concepto existente respecto a las relaciones entre poder técnico y ciudadanía en el diseño de un territorio, que se considera espacio vital para unos, mercancía inmobiliaria para otros, territorio que se debe gestionar para otros, etc. Estos intereses son los que interfieren una verdadera campaña de participación ciudadana y no tanto el discurso escrito o las expresiones orales de políticos y técnicos. Y aquí radica la pregunta que tiene que ver con la eficiencia de la participación ciudadana: ¿a quién se le concede la capacidad de decidir lo que es una opinión y un argumento para definir el modelo de desarrollo urbano futuro del lugar donde se vive?

A mi modo de ver la clave reside una vez más en los intereses subyacentes a las declaraciones formales del planeamiento, pues contra el parecer de ciertas opiniones el problema no reside en la falta de ordenación territorial, sino sobre todo en la manera de aplicar los criterios. Ello lo podemos ver otra vez en el caso de Vigo.

Ya en su proceso histórico, como pretendí demostrar en mi tesis doctoral, el municipio de Vigo es un ejemplo evidente de las dificultades de adaptar el medio ecológico a los intereses mercantiles de los poderes hegemónicos. Los ejemplos de la planificación de la conexión ferroviaria al puerto de Vigo, el propio emplazamiento de éste, los proyectos faraónicos de Antonio Palacios y el rechazo explícito de los principales propietarios o la pugna por la densificación de la margen derecha de la Gran Vía (la que se proyecta sobre el valle de Fragoso) serían pruebas empíricas de los desacuerdos entre los proyectos técnicos y los intereses crematísticos, un juego que acabó con un proceso jurídico y la condena de un concejal en pleno franquismo (Souto, 1990).

También como quise mostrar en un breve artículo sobre el plan general actual (Souto, 2005), la historia se repite con diferentes actores personales, pero con semejantes roles. Lo que ahora sucede es un enfrentamiento entre las interpretaciones de los técnicos de la Consellería de Ordenación del Territorio de la Xunta de Galicia y los técnicos redactores, que como hemos visto se pliegan a los intereses de los grupos políticos dominantes cuando es menester (caso del tramo de A Ronda). Si antes era el Ministerio de Vivienda (plan de 1972) ahora es la Xunta de Galicia. 
Un enfrentamiento que ya provocó una agria disputa en el año 2004, que supuso el traslado de técnicos municipales díscolos con el equipo de gobierno a otros puestos de trabajo que no pudieran interferir en la defensa de las posiciones municipalistas. Pues lo que sucedía, como en el plan anterior, era la territorialización de los intereses: la defensa de Vigo frente a las injerencias de Madrid en un caso y de Santiago de Compostela en otro (el "todos" y el "cada uno" que antes se comentaba, o sea el recurso al interés general que tantas veces nos recuerdan los políticos profesionales).

Si en julio y noviembre de 2004 las polémicas se centran en las densidades de edificabilidad y en el cálculo de la población futura, en el caso de agosto y septiembre de 2006 el conflicto surge por la aplicación de la normativa europea respecto a la evaluación ambiental de los planes de urbanismo (a través de la Ley 9/06), así como la restricción de edificar en determinados espacios que se consideran "suelo rústico de protección de costas". Como se ve, la interferencia de escalas genera nuevas argumentaciones y razonamientos que pueden provocar la creación de una opinión crítica. Las normas de la UE entran en el debate local y eso supone agitar las emociones del localismo identitario.

La defensa del equipo de gobierno, a través da Xerencia Municipal de Urbanismo, es muestra inequívoca de lo que decimos: "incompetencia do Director Xeral de Urbanismo para a resolución de acordos de suspensión na tramitación de procedemento de aprobación do plan xeral de ordenación municipal de Vigo". A continuación se argumenta que el plan tiene su propio estudio de sostenibilidad y, por tanto, no cabe requerirle que haga un nuevo informe.

Los documentos que reflejan la polémica técnica e institucional nos podría ocupar una amplia extensión de exposición analizando los motivos de unos y otros. Pero no queremos caer en esta trampa. Lo que nos interesa conocer es cuáles son los motivos reales del cambio de ordenamiento territorial, más allá de la adecuación de los instrumentos legales a las nuevas normativas elaboradas por los diferentes parlamentos competentes. En la respuesta a la alegación 19931 (modelo 054) encontramos una de las claves para mi entender más significativa: "o mencionado PERI Mantelas-Salgueira coa tipoloxía prevista era imposible levar adiante a transformación desas áreas"; en efecto, mientras que el Plan de 1993 incluía este PERI en la tipología de vivienda unifamiliar, el plan ahora propuesto utiliza la edificación de bloques y elimina todas las viviendas existentes. La clave reside en preguntarse cuáles son los motivos por los cuales no se ejecutan determinadas figuras de planeamiento: estudios de detalle, planes especiales de reforma interior, unidades de 
actuación, etc. No cabe preguntarse legítimamente que a los vecinos no les interesa construir en esos espacios. ¿Por qué todos los espacios deben ser transformados atendiendo a las plusvalías que deben generar?

Este debe ser el motivo por el que algunos vecinos dicen que el plan es un instrumento de especulación. Pese a que la contestación del equipo técnico es incuestionable desde el punto de vista de la retórica (alusión a que el alegante "non ten ben configurado o concepto de Especulación nin a relación que esta pode ter verbo das alturas da edificación"; alegación 4795, modelo 047), seguimos con la duda razonable de entender que este instrumento de planeamiento territorial sí que puede establecer los mecanismos para transformar un bien de uso espacial en una mercancía, pese a los argumentos del informe del equipo redactor: "un Plan Xeral non especula nin contén especulación porque a súa regulación, axustada aos criterios existentes da Lei, ordena equilibradamente a clasificación e cualificación do territorio municipal".

Las sospechas de este vecino que alegaba sobre la capacidad de un plan general para desarrollar un proceso inmobiliario especulativo responden a una intuición asentada en la opinión pública: existen intereses ocultos de carácter privado bajo la apariencia de una racionalidad territorial colectiva. La tarea de los proyectos de investigación es sacar a la luz los entresijos de esos elementos ocultos.

\section{5.- Más metodología en el uso de las técnicas de gestión territorial}

Casi a modo de cierre diríamos que una conclusión que se puede extraer de las diferentes lecciones derivadas de la crisis del modelo de crecimiento impulsado por las políticas europeas es la necesidad de un mayor rigor metodológico. Son modelos de gestión que se han generado en un contexto territorial concreto (la Unión Europea), pero que para trasladar a otros medios, con diferente escala territorial, precisan un estudio más específico. No sólo por la temática, sino sobre todo por el necesario estudio de la percepción de las personas en su participación ciudadana; los análisis realizados en el marco educativo (Harber y Meighan, 1989; Castorina y Lenzi, 2000; Reid et al., 2008) nos muestran evidencias de la verdadera participación ciudadana si somos capaces de interpretar el conocimiento espontáneo e interpretar las representaciones sociales. Algo que en Geografía y ordenación 
del territorio conocemos, al menos desde los años sesenta del siglo $\mathrm{XX}$, a través de las escuelas de la Percepción y el Comportamiento y que tiene su complemento en la Sociología (Boira, 2000, 2003; Martínez, 2002).

Para poder entender la gestión del territorio, sobre todo en espacios extensos y heterogéneos, necesitamos precisar la metodología que queremos utilizar para diagnosticar los problemas y orientar en las acciones futuras. En la actualidad se ha avanzado mucho en el uso de técnicas, en especial las derivadas del proceso de la información por medios telemáticos, de análisis territorial, pero menos se han desarrollado las metodologías que tengan en consideración las estrategias de gestión que surgen de los núcleos de poder político, financiero y cultural. Es preciso avanzar en los métodos cualitativos (Perecman, 2006) y en la interpretación de las ideas y deseos de las personas (Honneth, 2011), así como también en el análisis de la percepción política de la ordenación territorial (Díaz y Parreño, 2008). Un desarrollo que es necesariamente interdisciplinario y que afecta al debate político (Souto, 2011).

Para explicar cómo afectan a las nuevas formas de gestión territorial las políticas de austeridad económicas impuestas por las autoridades del Fondo Monetario Internacional, el Banco Europeo y la Comisión Europea es preciso relacionar el proyecto de construcción europea con las directrices económicas asignadas a los territorios, que se conciben como "contenedores de recursos", pero al mismo tiempo se pueden analizar las posibilidades de gestión que existen en unas instituciones que están pagadas con el dinero de los impuestos de sus ciudadanos.

En un trabajo semejante a éste, Raul Marques y quien firma el presente trabajo, hemos comparado las estrategias territoriales de dos euro-regiones (Galiza-Norte de Portugal y Andalucía-Algarve-Alentejo) para comprobar empíricamente la relevancia de la participación social en la interpretación de las políticas europeas. De esta forma pudimos explicar cómo el asociacionismo social determinó la ejecución de los objetivos, mientras que en los territorios donde sólo existía una representación institucional el logro de las metas fue mucho menor. Se constataba así la primera de las lecciones, donde la imagen social del territorio es un elemento sustancial a la hora de promover el desarrollo local.

En segundo lugar, como hemos podido analizar, el respeto a las diferencias ecológicas y culturales no puede suponer el establecimiento de desigualdades en relación con jergas tecnocráticas, como gobernanza, policentrismo, competitividad o convergencia. Y aquí aparece la responsabilidad de los investigadores, técnicos y académicos que trabajan en la 
gestión del territorio. Nos referimos en concreto a la posibilidad, o no, de hacer visibles las desigualdades para que sean objeto de de debate y su posterior incorporación al discurso deliberativo sobre la actuación futura. La práctica de la democracia en el urbanismo supone, como también ocurre en la educación (Harber y Meighan, 1989), decodificar la jerga que oculta y dificulta el análisis territorial, de acuerdo con las críticas de Jordi Borja (2012), como hemos señalado.

Explicar la gestión territorial supone un compromiso cívico con la justicia social. Para ello es preciso considerar las representaciones sociales que existen sobre el medio ecológico, los equipamientos públicos o las infraestructuras territoriales. Supone penetrar en el espacio subjetivo y percibido por los individuos en colectividad. Por eso hemos ligado nuestra argumentación geográfica con un posicionamiento ético y educativo. Sólo una educación crítica y hermenéutica puede hacer recuperar el valor de las palabras para gestionar el territorio. Y este es el gran desafío de la gestión territorial desde una perspectiva metodológica.

\section{Referencias bibliográficas}

ARMAS QUINTÀ, Francisco J. (2001) "Souto González, X.M. (dir.) <Planeamento estratéxico e mercadotécnia territorial. Eixo Atlántico do Noroeste>" Biblio 3W, Revista Bibliográfica de Geografía y Ciencias Sociales, Vol. VI, no 327.

BALEIRAS, Rui Nuno. Caminhos para a política de coesão 2014/2020, Eixo Atlântico. Revista da Eurorrexión Galicia-Norte de Portugal, no 16, 2009, páginas 17-48.

BOIRA MAIQUES, José V. (2000) Participar para conocer. Argumentos para la innovación en la participación ciudadana y la construcción de la ciudad", Scripta Nova. Revista Electrónica de Geografía y Ciencias Sociales, Universidad de Barcelona, n. 69 (77)

BOIRA MAIQUES, José V.(2003) La participacion ciudadana y el urbanismo. ¿Racionalizar la democracia o democratizar el espacio? En CAPEL, Horacio (coordinador). Ciudades, arquitectura y espacio urbano, Almería: Cajamar, páginas 317-334

BORJA, Jordi (2012). El fin de la anticiudad posmodernista y el derecho a la ciudad en las regiones metropolitanas, En Belil, M.; Borja, J. y Corti, M (eds) Ciudades, una ecuación imposible, Barcelona: Icaria y Fundació Forum, pp. 279-320

CAPEL SÁEZ, Horacio (1973). Percepción del medio y comportamiento geográfico. Revista de Geografía, núm. 7, Univ. de Barcelona, pp. 58-150.

CASTORINA, J.A. y LENZI, A.M. (Comps.) (2000) La formación de los conocimientos sociales en los niños. Investigaciones psicológicas y perspectivas educativas. Barcelona: Gedisa.

COMISIÓN EUROPEA (2001) Unidade da Europa, Solidariedade dos povos, diversidade dos territórios, Segundo relatório sobre a coesão económica e social, Luxemburgo, Comunidades Europeas. Dous volumes e Anexo estatístico. 
COMISIÓN EUROPEA (2004) Construir nuestro futuro común: retos políticos y medios presupuestarios de la Unión ampliada 2007-2013, COM (2004) 101. En COMISION EUROPEA: Una nueva asociación para la cohesión. Tercer informe sobre la cohesión económica y social, Luxemburgo, Comunidades Europeas.

DE LA PUENTE FERNÁNDEZ, Leonor (2000). Geografía e Historia del Eje Atlántico, Biblio 3W, Revista Bibliográfica de Geografía y Ciencias Sociales, № 204.

DÍAZ HERNÁNDEZ, R. y PARREÑO CASTELLANO, J. M (2008). Territorio, participación ciudadana y nivel de confianza en las instituciones oficiales. Scripta Nova. Revista Electrónica de Geografía y Ciencias Sociales. Barcelona: Universidad de Barcelona, 1 de agosto de 2008, vol. XII, núm. 270 (116)

DOMÍNGUEZ, Luis; VENADE, Nuno (2004). As euro-regiões e o futuro da Europa: o modelo da euro-região Galiza-Norte de Portugal, Vigo-Porto: Eixo Atlántico do Noroeste peninsular.

FARINÓS, J y ROMERO, J. (2007) (Coords): Territorialidad y buen gobierno para el desarrollo sostenible. Nuevos principios y nuevas políticas en el espacio europeo. Publicacions de la Universitat de Valencia.

HABERMAS, J.(1987) Teoría de la acción comunicativa. Madrid: Taurus.

HARBER, Clive; MEIGHAN, Roland (1989). The democratic school. Educational management and the practice of democracy, Ticknall: Education Now Publishing.

HART, R. (1993). La participación de los niños: de la participación simbólica a la participación auténtica. Bogotá: Nueva Gente.

HARVEY, David (2013). Ciudades Rebeldes, Madrid: Akal.

HONNETH, A.(2011)La sociedad del desprecio. Madrid: Editorial Trotta.

JODELET, D. (1986) La representación social: fenómenos, concepto y teoría. En S. Moscovici (Ed.), Psicología Social, II: Pensamiento y vida social. Psicología social y problemas sociales, Barcelona: Paidós, págs. 469-494 (Edic. orig. Psychologie Sociale. París: P.U.F., 1984).

MC CARTHY, T. (1987) La teoría crítica de Jürgen Habermas, Madrid: Tecnos.

MAÑERO MIGUEL, Fernando (2010). La participación ciudadana en la ordenación del territorio : posibilidades y limitaciones, Cuadernos Geográficos, 47-2, páginas 47-71

MARQUES, Raul J.(1999) A organização política do território, In Souto González, Xosé M. ( coord.) A Historia no Eixo Atlántico, Vigo, Eixo Atlántico do Noroeste Peninsular, pp. 199-272

MARTÍNEZ LÓPEZ, Miguel.(2002) Laberintos y laboratorios de participación urbana: una aventura de investigación social comparativa y dialéctica. Scripta Nova. Revista elctrónica de geografía y ciencias sociales, Universidad de Barcelona, vol. 6 núm. 130

MOSCOVICI, S. (Ed.)(1975) Introducción a la psicología social. Barcelona: Planeta. (Edic. Original : Introduction à la psychologie sociale. Vol. I y II. París: Larousse, 1972).

PARDELLAS DE BLAS, Xulio (director) (2002) Abordagem á actividade turística nas cidades do Eixo Atlântico, Vigo, Eixo Atlántico do Noroeste Peninsular.

PAÜL CARRIL, Valerià (2001). Nuevas aportaciones en Internet sobre o Eixo Atlántico, Biblio 3W, Revista Bibliográfica de Geografía y Ciencias Sociales, № 268.

PERECMAN, E. (2006). A handbook for social science field research: essays \& bibliographic sources on research design and methods. Thousand Oaks, Calif; London: Sage.

PINDADO, Fernando (2008) La participación ciudadana es la vida de las ciudades, Barcelona. Ediciones del Serbal.

REID, Alan et al. (2008) Participation and Learning. Perspectives on Education and the Environment, Health and Sustainability, Bath: Springer.

ROMERO GONZÁLEZ, Juan y FARINÓS DASÍ, Joaquín (editores)(2004). Ordenación del territorio y desarrollo territorial. El gobierno del territorio en Europa: tradiciones, contextos, culturas y nuevas visiones, Gijón: Ediciones Trea, S.L.

SOUTO GONZÁLEZ, X. M.(1990) Vigo cen anos de historia urbana (1880-1980), Vigo: Xerais. 
SOUTO GONZÁLEZ, X. M. (coord.) (1999) Xeografía do Eixo Atlántico, Vigo, Eixo Atlántico do Noroeste Peninsular.

SOUTO GONZÁlEZ, X. M. (coord.) (1999) A Historia no Eixo Atlántico, Vigo, Eixo Atlántico do Noroeste Peninsular.

SOUTO GONZÁLEZ, X. M. (coord.) (2001) Planeamento estratéxico e mercadotecnia territorial, Vigo, Eixo Atlántico do Noroeste Peninsular.

SOUTO GONZÁLEZ, X. M., e MARQUES, Raul Jorge (coord.) (2003) Participación cidadá e desenvolvemento local no no Eixo Atlántico: Monforte e Chaves, Vigo, Eixo Atlántico do Noroeste Peninsular.

SOUTO GONZÁlEZ, X. M. BOUZADA FERNÁNDEZ, Xan, FIGUEIREDO FIGUEIREDO, Antonio (2005). Estudos estratéxicos do Eixo Atlántico, Vigo: Eixo Atlántico do Noroeste Peninsular.

SOUTO GONZÁLEZ, X. M. (2005) A ordenación do territorio: proxectos públicos e intereses privados. A propósito do Plano Xeral de Ordenación Municipal de Vigo, Boletín do Instituto de Estudos Vigueses, número 11 ,

p.

99-115

SOUTO GONZÁLEZ, X. M. (2005) Euro-rexións e cidadania no noroeste peninsular. Biblio 3W, Revista Bibliográfica de Geografía y Ciencias Sociales, Universidad de Barcelona, Vol. X, no 605.

SOUTO GONZÁLEZ, X. M. (2006) La estrategia territorial europea: racionalización o privatización del espacio geográfico. Biblio 3W Revista Bibliográfica de Geografía y Ciencias Sociales, Universidad de Barcelona, Vol. XI, no 664 .

SOUTO GONZÁLEZ, X. M. (2006) Participación ciudadana y ordenación del territorio. Biblio 3W Revista Bibliográfica de Geografía y Ciencias Sociales, Universidad de Barcelona, Vol. XI, no 677.

SOUTO GONZÁLEZ, Xose M (2011). El movimiento 15-M y el debate sobre el Estado y la violencia en los cambios sociales. Biblio 3W. Revista Bibliográfica de Geografía y Ciencias Sociales. [En línea]. Barcelona: Universidad de Barcelona, vol. XVI, no 932 (8).

SOUTO GONZÁLEZ, X.M. y MARQUES, Raul J. (2014). Planeamiento territorial a diferentes escalas. Eixo atlântico do noroeste peninsular y Bacia do Guadiana, In Ayllón Trujillo, Mạ Teresa (editora). Conflictos de poder sobre el espacio. Manual de ordenación territorial a diferentes escalas, Universidad Autónoma San Luis de Potosí y Consejo Nacional de Ciencia y Tecnología, Málaga: Eumed, pp. 227-272

VILLARES PAZ, Ramón (2010). De Gallaecia a Eurorrexión, In POMBO, Ernesto. Unha eurorrexión entre dous séculos, Vigo: Eixo Atlántico do Noroese peninsular, pp. 15-28 